\title{
New advances in catalysts for polystyrene hydrogenation
}

\author{
Ruoyi $\mathrm{Xu}^{1}$, Qianwen $\mathrm{Li}^{1}$, Hui Huang ${ }^{1}$ and Shiying $\mathrm{Tao}^{2,3^{*}}$ \\ ${ }^{1}$ School of Materials and Chemical Engineering, Ningbo University of Technology, Ningbo, Zhejiang, 315211, P R China \\ ${ }^{2}$ Faculty of Science and Engineering, The University of Nottingham Ningbo China, Ningbo, Zhejiang, 315100, P R China \\ ${ }^{3}$ Ningbo Nottingham New Materials Institute Ltd., Ningbo, Zhejiang, 315040, P R China
}

\begin{abstract}
Polystyrene is one of the most widely used plastics, and could be catalytic hydrogenated to polycyclohexylethylene with improved physical properties. The research progress in the efficiency palladium catalyst for polystyrene hydrogenation was illustrated and reviewed, further development was discussed.
\end{abstract}

\section{Introduction}

Polystyrene is a polymer obtained by addition polymerization of styrene, which is also the most widely used thermoplastic at present. It has many advantages such as water resistance, corrosion resistance, high transparency, easy coloring, easy processing and molding. As one of the five general plastics, polystyrene is widely used in electronic communication, mold, food packaging and daily use Products and other major fields. When the unsaturated bond of benzene ring in polystyrene is catalysed and hydrogenated, the polycyclohexylethylene with better physical properties can be obtained.

The study of catalytic hydrogenation of polystyrene began in 1929. Raney $\mathrm{Ni}, \mathrm{Rh} / \mathrm{C}, \mathrm{Ni} / \mathrm{Kieselgur}, \mathrm{Pd} / \mathrm{CaCO}_{3}$ and other catalysts were used for polymerization. However, due to the poor catalytic system, the catalytic hydrogenation of polystyrene resulted in chain breaking and the decrease of molecular weight, which directly affected the performance. In order to solve the problem of chain breaking in the hydrogenation of polystyrene and alleviate the harsh hydrogenation reaction conditions, scholars have made a series of explorations and researches in improving hydrogenation catalyst and optimizing hydrogenation process conditions, which was well illustrated in the previous literature[1]. The hydrogenation of polystyrene has vitnessed a rapid development in recent years, the milestone achievements and recent results of the catalytic reaction by the heterogeneous catalysts are demonstrated in this paper.

\section{Palladium catalysts for polystyrene hydrogenation}

\subsection{Magnetic palladium catalyst}

Magnetic palladium catalyst was synthesized by in situ method with ferroferric oxide as magnetic core. The kinetic model indicated that hydrogenation of polystyrene to polycyclohexylethylene over magnetic palladium catalyst was first order with respect to polystyrene and zero order with respect to hydrogen. The activation energy was $51.4 \mathrm{~kJ} / \mathrm{mol}$, and the prepared magnetic palladium catalyst showed a good magnetic separation ability[2].

\subsection{Silica microspheres supported palladium catalyst}

Silica hollow microspheres with size-tunable penetrating macropores from $250 \mathrm{~nm}$ to $560 \mathrm{~nm}$ were prepared by a water/oil/water ternary phase emulsion system, which can serve as a superior support to fabricate supported palladium catalysts for hydrogenation of bulky polystyrene molecules[3]. The hydrogenation reaction was confirmed to be a first-order reaction and the activation energy was calculated to be $58.3 \mathrm{~kJ} / \mathrm{mol}$. It was proved that polystyrene heterogeneous hydrogenation process existed secondary adsorption and competitive adsorption phenomenon and obeyed the Blocky mechanism[4].

Macroporous silica microspheres materials with penetrating meso/macroporous shells were prepared by a ternary emulsion method, and were treated with steam first to remove mesopores and then refluxed with ammonia solution to increase silanol groups on surface for Pd immobilization. The removal of mesopores and the maintenance of macroporous structure can effectively enhance the accessibility of polystyrene molecules to active sites. The corresponding catalyst showed superior hydrogenation activity[5].

\subsection{Barium sulfate supported palladium catalyst}

Barium sulfate carriers with or without mesopore structure were synthesized via precipitation reaction in aqueous solution of barium hydroxide and sulfuric acid 
with ethylene glycol as a modifying agent. The obtained barium sulfate was used as catalyst carriers and the barium sulfate supported palladium catalyst was prepared by using impregnation method. It was found that the barium sulfate supported palladium catalyst without mesopores had palladium grains deposited on the external surface of the carrier, reducing the pore diffusion of polystyrene coils, and enabled more active sites to participate in the hydrogenation reaction with a better activity[6].

\subsection{Monolithic $\mathrm{TiO}_{2}$ ceramic foam supported palladium catalyst}

The monolithic ceramic foam was synthesized through uniform coating of $\mathrm{TiO}_{2}$ on synthetic template and partial sintering, and was utilized as support in the preparation of palladium catalyst by an equilibrium impregnation method. The palladium nanoparticles were located on the surface of the $\mathrm{TiO}_{2}$ ceramic base. The Weisz modulus of less than 0.3 indicating that internal diffusion limitation inside the catalyst could be neglected for unique macropores on the struts[7].

\subsection{Carbon nanotubes supported palladium catalyst}

The carbon nanotube supported palladium catalysts were synthesized by the impregnation method and applied in the hydrogenation of commercial polystyrene. The results showed that the active metal deposited on the external surface of carbon nanotubes with good dispersion and the TOF was much higher than that of comparison catalysts, e.g., $\mathrm{Pd} / \mathrm{AC}$ or $\mathrm{Pd} / \mathrm{BaSO}_{4}$. The high external surface area and the interaction between polymer and carbon nanotubes could be the reason for the high performance[8].

Cordierite honeycomb ceramic was modified by high-temperature calcination and hydrofluoric acid instantaneous etching, and then used to synthesis carbon nanotube supported palladium catalyst. High-temperature calcination eliminated internal pores of ceramic framework and ceramic surface became flat and dense. Instantaneous etching increased surface roughness and facilitated carbon nanotube growth on the surface. Carbon nanotubes growing on structure-modified cordierite monolith surface significantly improved homogeneous dispersion of palladium and subsequently enhanced hydrogenation performance[9].

Structured catalyst support was fabricated by in situ immobilization of carbon nanotubes layer on the nickel foam surface via chemical vapor deposition method. The palladium catalyst supported on carbon nanotubes decorated nickel foam was directly employed as the catalytic stirrer in a rotating foam stirrer reactor for polystyrene hydrogenation. The improved performance suggesting the enhanced liquid-solid mass transfer in the rotating foam stirrer reactor with the merits of eliminating the filtration operation[10]. While the entangled carbon nanotubes layer with open pores and the dense carbon layer beneath covered around the skeleton of nickel foam, the palladium catalyst supported on carbon nanotube modified nickel foam establish a hybrid hierarchical structure with large effective surface area and promoted the internal diffusion of large polystyrene coils[11]. The average diameter and graphitization degree of carbon nanotubes could be tuned by adjusting the chemical vapor deposition temperature and its surface area and interaction with polystyrene molecules. The high performance of the catalyst could be contributed to the non-porous and wide-open structure of carbon nanotubes layer and strong $\pi-\pi$ interaction between carbon nanotubes surface and polystyrene molecules which facilitated the diffusion and adsorption of polystyrene coils respectively[12].

Fe doped ceramic foam was synthesized by organic template replication and modified by carbon nanotubes via facile chemical vapor deposition. Carbon nanotubes were in situ anchored on the surface of the foam with excellent mechanical stability. Palladium nanoparticles were deposited onto carbon nanotube modified Fe doped ceramic foam forming a structured catalyst. The catalyst showed an outstanding catalytic activity could be ascribed to the accessible effective palladium active sites with high dispersion and enhanced adsorption of polystyrene chains onto the carbon nanotube surface[13].

\subsection{Conditions of polystyrene hydrogenation experiments}

The name of palladium catalysts, weight average molecular weight of polystyrene, reaction pressure and temperature, solvent and activation energy of hydrogenation experiments were summarized in Table 1 . As shown in Table 1, two kinds of polystyrene with weight average molecular weight of $279000 \mathrm{~kg} / \mathrm{mol}$ and $250000 \mathrm{~kg} / \mathrm{mol}$, respectively, were used for hydrogenation. The hydrogenation pressure was raged from 5.0 to 7.0 MPa, and The hydrogenation temperature was in the range of 90 to $180{ }^{\circ} \mathrm{C}$. Tetrahydrofuran/cyclohexane mixture with different volume ratio or decahydronaphthalene were used as solvent in the hydrogenation. The activation energy of polystyrene hydrogenation was $53.5 \pm 3.3 \mathrm{~kJ} / \mathrm{mol}$.

Table 1. Comparasion of hydrogenation experiments over different palladium catalysts.

\begin{tabular}{|c|c|c|c|c|c|c|}
\hline Catalyst & Polystyrene & Pressure & Temperature & Solvent & $\begin{array}{l}\text { Activation } \\
\text { Energy }\end{array}$ & Reference \\
\hline $\mathrm{Pd} / \mathrm{SiO}_{2}$-org/Fe $3 \mathrm{O}_{4}$ & $\mathrm{M}_{\mathrm{w}}=279000$ & $5.5 \mathrm{MPa}$ & $120-170^{\circ} \mathrm{C}$ & Decahydronaphthalene & $51.4 \mathrm{~kJ} / \mathrm{mol}$ & [2] \\
\hline S9-Pd/SHMs & $\mathrm{M}_{\mathrm{w}}=250000$ & 7.0 $\mathrm{MPa}$ & $150^{\circ} \mathrm{C}$ & $\begin{array}{c}10 \mathrm{v} \% \text { Tetrahydrofuran/ } \\
90 \mathrm{v} \% \text { cyclohexane mixture }\end{array}$ & / & [3] \\
\hline $\mathrm{Pd} / \mathrm{SHMs}$ & $\mathrm{M}_{\mathrm{w}}=250000$ & 7.0 MPa & $90-180{ }^{\circ} \mathrm{C}$ & $20 \mathrm{v} \%$ Tetrahydrofuran/ & $58.3 \mathrm{~kJ} / \mathrm{mol}$ & [4] \\
\hline
\end{tabular}




\begin{tabular}{|c|c|c|c|}
\hline Pd/Ram-MSM & $\mathrm{M}_{\mathrm{w}}=250000$ & $5.0 \mathrm{MPa}$ & \\
\hline $\mathrm{Pd} / \mathrm{BSC}-6 \mathrm{H}$ & $\mathrm{M}_{\mathrm{w}}=279000$ & $5.5 \mathrm{MPa}$ & \\
\hline $\mathrm{Pd} / \mathrm{CFs}$ & $\mathrm{M}_{\mathrm{w}}=279000$ & $5.8 \mathrm{MPa}$ & \\
\hline $\mathrm{Pd} / \mathrm{CNTs}$ & $\mathrm{M}_{\mathrm{w}}=279000$ & $5.8 \mathrm{MPa}$ & \\
\hline Pd/CNTs@CHC & $\mathrm{M}_{\mathrm{w}}=279000$ & $5.8 \mathrm{MPa}$ & \\
\hline Pd/CNTs@NF & $\mathrm{M}_{\mathrm{w}}=279000$ & $5.8 \mathrm{MPa}$ & \\
\hline Pd/CNTs@NF & $\mathrm{M}_{\mathrm{w}}=279000$ & $5.8 \mathrm{MPa}$ & \\
\hline Pd/CNTs@NF & $\mathrm{M}_{\mathrm{w}}=279000$ & $5.8 \mathrm{MPa}$ & \\
\hline Pd/CNTs@CFs & $\mathrm{M}_{\mathrm{w}}=279000$ & $5.8 \mathrm{MPa}$ & \\
\hline \multicolumn{4}{|c|}{ Conclusions } \\
\hline \multicolumn{4}{|c|}{$\begin{array}{l}\text { ver the past decades, researchers managed to develop } \\
\text { eries of efficiency palladium catalysts for polystyrene } \\
\text { ydrogenation. Improvements in the performance of the } \\
\text { alladium catalyst were based on the recognition of the } \\
\text { nportance of polystyrene-support, metal-support } \\
\text { ynergy. It is believed that further development of a } \\
\text { holecular understanding of catalytic action would create } \\
\text { basis for a rational design of new and improved } \\
\text { olystyrene hydrogenation catalysts. }\end{array}$} \\
\hline
\end{tabular}

\section{Acknowledgments}

Authors wish to acknowledge financial support from Department of Education of Zhejiang Province(Y201941937), Zhejiang Xinmiao Plan(2018R428012) and Ningbo Natural Science Foundation(2017A610066).

\section{References}

1. Huang H., Fan Y.F., Tao S.Y., Gao H.Q. (2013) Progress in catalytic hydrogenation of polystyrene to poly(cyclohexylethylene). New. Chem. Mater., 4: 178-179,181.

2. Huang H., Zhou J.T., Ying Q.R., Tao S.Y. (2014) Preparation of magnetic palladium catalyst and its kinetic study of polystyrene hydrogenation. Modern Chem. Ind., 4: 70-73.

3. Pan D., Shi G., Zhang T., Yuan P., Fan Y., Bao X.J. (2013) New understanding and controllable synthesis of silica hollow microspheres with sizetunable penetrating macroporous shells as a superior support for polystyrene hydrogenation catalysts. J. Mater. Chem. A, 1: 9597-9602.

4. Yuan P., Chen J., Pan D., Bao X.J. (2016) Adsorption and reaction kinetic studies of the heterogeneous catalytic hydrogenation for polystyrene. Acta Chim. Sin., 7, 603-611.

5. Chen J., Hu Y.D., Cai A.F., Cheng T.T., Wu Z.J., Liu H.Y., Bao X.J., Yuan P. (2018) The mesoporeelimination treatment and silanol-groups recovery for macroporous silica microspheres and its application as an efficient support for polystyrene hydrogenation. Catal. Commun., 111: 75-79.
6. Han K.Y., Meng C., Zhu Z.W., Cao G.P. (2014) Hydrogenation of commercial polystyrene over $\mathrm{Pd} / \mathrm{BaSO}_{4}$ catalysts: effect of carrier structure. Trans. Tianjin Univ., 20: 282-291.

7. Han K.Y., Cao G.P., Zuo H.R., Guo W.Z., Zhu Z.W., Lu C., Wang Y.H. (2015) Hydrogenation of commercial polystyrene on $\mathrm{Pd} / \mathrm{TiO} 2$ monolithic ceramic foam catalysts: catalytic performance and enhanced internal mass transfer. Reac. Kinet. Mech. Cat., 114: 501-517.

8. Han K.Y., Zuo H.R., Zhu Z.W., Cao G.P., Lu C., Wang Y.H. (2013) High performance of palladium nanoparticles supported on carbon nanotubes for the hydrogenation of commercial polystyrene. Ind. Eng. Chem. Res., 52: 17750-17759.

9. Li C.Y., Feng M., Cui H.F., Cao G.P., Lu H., Chen R.Q. (2017) Preparation of carbon nanotube catalyst on structure-modified cordierite monolith for polystyrene hydrogenation. CIESC J., 7: 2746-2755.

10. Feng M., Luo Z.H., Yi S., Lu H., Lu C., Li C.Y., Zhao J.L., Cao G.P. (2018) Palladium supported on carbon nanotubes decorated nickel foam as the catalytic stirrer in heterogeneous hydrogenation of polystyrene. Ind. Eng. Chem. Res., 57: 16227-16238.

11. Feng M., Luo Z.H., Chen R.Q., Yi S., Lu H., Cao G.P., Lu C., Feng S.Y., Li C.Y. (2019) Palladium supported on carbon nanotube modified nickel foam as a structured catalyst for polystyrene hydrogenation. Appl. Catal. A Gen., 570: 329-338.

12. Feng M., Luo Z.H., Cao G.P., Lu H. (2019) Tunable growth of carbon nanotubes forests on nickel foam as structured support for palladium catalyst toward polystyrene hydrogenation. J. Taiwan Inst. Chem. Eng., 97: 119-127.

13. Feng M., Lu H., Li C.Y., Cao G.P. (2019) Carbon nanotube modified ceramic foams as structured palladium supports for polystyrene hydrogenation. Ind. Eng. Chem. Res., 58: 10793-10803. 